\title{
Study of bacterial flora in perianal region and vagina and relation to neonatal outcome
}

\author{
Sultan R ${ }^{1}$, Harit $\mathbf{J}^{2}$, Roy PK ${ }^{3}$ \\ ${ }^{1}$ Dr Razia Sultan, Assistant Professor, ${ }^{2}$ Dr. Juhee Harit, Ex Resident, ${ }^{3}$ Dr P. K. Roy Professor Department of Obstetrics, R.D. \\ Gardi Medical College, Ujjain, MP, India
}

Corresponding Author: Dr. Juhee Harit Ex resident, Department of Obstetrics, R.D. Gardi Medical College, Ujjain, MP, India

\begin{abstract}
Objectives: Studyof bacterial flora in perianal region and vagina and relation to neonatal outcome and sepsis. Methodology: After taking detailed history, doing a general physical \& obstetric examination and routine antenatal investigations, all the patients were subjected to special investigations. Results: Out of 17 neonatal septic babies 4 babies mother have PROM with significant $\mathrm{p}$ value 0.03. 4 mothers have prolonged labor with significant $\mathrm{p}$ value 0.03 . Out of 17 neonatal septic babies 5 mothers have $\mathrm{H} / \mathrm{O}$ multiple $\mathrm{P} / \mathrm{V}$ examination with significant $\mathrm{p}$ value 0.04 . One patient had history of fever. 10 mothers had Preterm delivery which is statistically not significant $\mathrm{p}$ value 0.118 . The data were analyzed using the Pearson's chi square test, macnemar chi square test. Conclusion: From the study it was concluded that there is a certain degree of correspondence between the vaginal and rectal microflora. Microbial colonization of the maternal genital tract is a key factor in most cases of sepsis. Although prevalence study reports a predominance of Gram negative bacilli among female genital colonizers and Gram-negative sepsis among their infants.
\end{abstract}

Key words: Microflora,Perianal, Sepsis. Colonization Escherichia coli Group B streptococcus

\section{Introduction}

Bacterial infections can influence pregnant women from implantation of the fertilized ovum throughout the peripartum period and time of delivery. They may also affect the fetus and newborn. Many women with these infections are asymptomatic, necessitating both a high degree of clinical awareness and adequate screening. Bacterial infections can be caused by a wide range of bacteria, resulting in mild to life-threatening illnesses such as bacterial meningitis that require immediate intervention. Common bacterial infections include pneumonia, ear infections, diarrhea, urinary tract infections, and skin disorders [1].

Both aerobic and microaerophilic organisms as well as the strictly anaerobic bacteria constituted the microflora of the lower genital of this group of women, Lactobacilli were the most frequently isolated organism in both the cervix and vagina. Proteus species were the least in incidence. The following pathogenic organisms were isolated in both the vagina and cervix: Escherichia coli, Staphylococcus aureus, Candida albicans, Clostridium

Manuscript received: $04^{\text {th }}$ December 2017

Reviewed: $10^{\text {th }}$ December 2017

Author Corrected: $15^{\text {th }}$ December 2017

Accepted for Publication: $22^{\text {nd }}$ December 2017

Obsgyne Review: Journal of Obstetrics and Gynecology species and Beta-haemolyticStreptococci. In general, the same types of organisms were isolated in both the cervical and vaginal samples [2].

The vaginal microflora in menarchal women (women in the reproductive age group between menarche and menopause) has been studied using direct microscopic observations, as well as quantitative and qualitative culture methods, for over 50 years.

More recently, 16S r DNA deep sequencing methods have also been applied to this component of the human microbiome. In menarchal, overtly healthy women, microscopic examination of vaginal samples indicates that a predominantly Gram-positive microflora is present. Qualitative cultures indicate that the dominant genus is Lactobacillus. Lactobacillus sp., particularly H2O2producing strains, have been cited as important indicators of a healthy vaginal environment [3].

It is clear that the microflora of the vagina is an important mediator of adverse pregnancy outcomes and may serve as the source for organisms that not only colonise the vagina, but also the placental tissues of the developing fetus.

Available online at : www.medresearch.in 56 | P a g e 


\section{Methodology}

This study was carried out in Department of Obstetrics \& Gynaecology, R.D Medical College \& associated Hospitals, Ujjain (M.P.). The present study has a social background mostly relevant to a woman's output in the antenatal period.

Study Population- Women attending C.R. Gardi Hospital, Obstetrics \& Gynaecology OPD are the study subjects. This hospital is mainly catering to the rural population. Majority of the women are socioeconomically backward, mostly illiterate. The study included 162 pregnant women admitted at term and in preterm labour.

The pregnant women who were on antibiotic intervention in the last trimester of pregnancy where excluded from the study population. The study was conducted in R.D. Gardi hospital for one year six months on 162 parturient women. Written informed consent taken from each of these participants.

Inclusion criteria: All patients in labour having labour pain and dilatation of cervix $>2 \mathrm{~cm}$

Exclusion criteria: Patient coming with diagnosed IUD or still birth

Ethical aspect: Before entering the trial patient was explained about the study and informed consent was taken. The institutional ethical committee cleared the proposal

Sample collection: Two swabs one from high vagina and the other from perianal region were collected from each study participant, before pelvic examination while taking standard precautions. Sterile cotton swab pre moistened with sterile saline was used for perianal region.

High vaginal swab were taken with speculum, by inserting the swab and rotating swab in circular motion, leaving in vagina for approximately 5 seconds. A separate perianal swab was taken by gently rotating the swab around the anal margin for approximately 5 seconds. Both the swabs were inoculated into Stuarts transport medium. All samples were transported to laboratory within 20 to 30 minutes and processed immediately.

Swabs were inoculated on Blood agar (BA) and MacConkey (Mac) agar and incubated at $37^{\circ} \mathrm{C}$ for 18 to $24 \mathrm{hrs}$. The isolates were identified using standard laboratory procedures including morphology, gram staining, culture characteristics and a panel of biochemical tests (Mac). Detailed information on maternal characteristics was noted by taking detailed history. Information obtained regarding the status of new born at delivery and examination by pediatrician.

\section{Interpretation of culture results}

- Any isolates obtained in pure luxuriant growth was considered as a significant colonization.

- Whereas scanty or mixed bacterial growth consisting of different bacterial colonies suggestive of commensal flora of vagina or perianal region was interpreted as insignificant.

- Heavy growth consisting of three or more than 3 organisms was classified as positive result with the suspicion of one of them might be a significant coloniser among the mixed bacterial population.

- Pure growth of Candia species was also considered as significant.

- Both, significant and insignificant culture results were subsequently correlated with the occurrence of early neonatal sepsis amongst babies of the study participants.

\section{Results}

- Out of 17 neonatal septic babies 4 babies mother have PROM with significant $\mathrm{p}$ value 0.03 .4 mothers have prolonged labor with significant $\mathrm{p}$ value 0.03 Out of 17 neonatal septic babies 5 mothers have $\mathrm{H} / \mathrm{O}$ multiple $\mathrm{P} / \mathrm{V}$ examination with significant $p$ value 0.04

- 1 mother have H/O fever which is statistically not significant $\mathrm{p}$ value 0.19 .3 mother have PA tenderness with significant $\mathrm{p}$ value 0.03 . 10 mother have Preterm delivery which is statistically not significant $p$ value 0.118

Statistical analysis- Data were entered in IBM SPSS Statistics 16.0 and analysed using descriptive statistics, frequencies and bivariate analysis (cross-tabulations). Chi-square test with Yates' correction was used as to compare the results. A significance level of $\mathrm{P}=0.05$ was used 
Table-1: Distribution according to mode of delivery

\section{Original Research Article}

\begin{tabular}{|l|l|l|}
\hline Mode of Delivery & No. of Women & Percentage \\
\hline Normal delivery & 120 & 74.1 \\
\hline Cesarean section & 35 & 21.6 \\
\hline Vacuum delivery & 6 & 3.7 \\
\hline Forceps delivery & 1 & 0.6 \\
\hline Total & $\mathbf{1 6 2}$ & $\mathbf{1 0 0 . 0}$ \\
\hline
\end{tabular}

$74.1 \%$ delivered normally, $21.6 \%$ delivered through cesarean section, $3.7 \%$ delivered through vacuum and $0.6 \%$ forceps delivered

Table-2: Distribution according to high vaginal culture

\begin{tabular}{|l|l|l|}
\hline Culture & No. of Women & Percentage \\
\hline Staphylococcus aureus & 37 & 22.8 \\
\hline E. coli & 38 & 23.4 \\
\hline Klebsiella pneumonia & 8 & 4.9 \\
\hline Pseudomonas & 5 & 3.1 \\
\hline Citrobacter & 8 & 4.9 \\
\hline Proteus vulgaris & 1 & 0.6 \\
\hline Candida & 6 & 3.7 \\
\hline Mixed growth & 7 & 4.3 \\
\hline Commensal flora & 50 & 30.5 \\
\hline Streptococci & 1 & 0.6 \\
\hline Non-fermenting gram negative bacilli & 1 & 0.6 \\
\hline Total & $\mathbf{1 6 2}$ & $\mathbf{1 0 0 . 0}$ \\
\hline
\end{tabular}

Table depicted staphylococcus aureus in \& E. coli in are most common organism isolated.

Table-3: Distribution according to perianal swab culture

\begin{tabular}{|l|l|l|}
\hline Culture & No. of Women & Percentage \\
\hline Staphylococcus aureus & 21 & 12.9 \\
\hline E. coli & 90 & 55.5 \\
\hline Klebsiella pneumonia & 2 & 1.2 \\
\hline Pseudomonas & 4 & 2.5 \\
\hline Citrobacter & 9 & 5.6 \\
\hline Proteus vulgaris & 2 & 1.2 \\
\hline Mixed growth & 7 & 4.3 \\
\hline Commensal flora & 28 & 17.2 \\
\hline Non-fermenting gram negative bacilli & 1 & 0.6 \\
\hline Total & $\mathbf{1 6 2}$ & $\mathbf{1 0 0}$ \\
\hline
\end{tabular}

Table depictedstaphylococcus aureus in \& E. coli in are most common organism isolated.

Table -4:Association between Maternal Risk Factors and Early Onset Septicemia

\begin{tabular}{|l|l|l|l|}
\hline Maternal risk factor & $\begin{array}{l}\text { No. neonatal sepsis } \\
(\mathbf{n = 1 7 )}\end{array}$ & P value & Significance \\
\hline PROM & 4 & 0.03 & Significant \\
\hline Prolonged labour & 4 & 0.03 & Significant \\
\hline MultipleP/V examination & 5 & 0.04 & Significant \\
\hline Maternal fever & 1 & 0.19 & Not significant \\
\hline PA tenderness & 3 & 0.03 & Significant \\
\hline Preterm delivery & 10 & 0.118 & Not significant \\
\hline
\end{tabular}


Original Research Article

Table-5: Distribution of babies according to neonatal sepsis diagnosis

\begin{tabular}{|l|l|l|}
\hline Neonatal Sepsis & No. of Babies & Percentage \\
\hline Yes & 17 & 11.7 \\
\hline No & 143 & 88.3 \\
\hline Total & $\mathbf{1 6 2}$ & $\mathbf{1 0 0 . 0}$ \\
\hline
\end{tabular}

Distribution of babies according to neonatal sepsis diagnosis: Neonatal sepsis was present in 17 (11.7\%) babies, 143 $(88.3 \%)$ babies were healthy.

\section{Discussion}

This is a descriptive observational study carried out in Department of Obstetrics \& Gynecology, R.D. Gardi Medical College, Ujjain and was conducted from September 2013 to July 2015. Total 162 subjects were recruited based on inclusion and exclusion criteria from antenatal clinic of OPD and IPD of our hospital with the aim is to study colonization of bacteria in vagina and perianal region in parturient women and its co-relation to development of neonatal sepsis

Early onset neonatal sepsis is associated with high neonatal morbidity and mortality. It is conventionally regarded as maternally acquired with causative organisms usually found in maternal genital tract. Of the 130 million babies born every year, about 4 million die in the first 4 weeks of life. Most neonatal deaths (99\%) arise in developing countries, like, India and about half occur at home. Globally, the main direct causes of neonatal deaths are estimated to be preterm birth (28\%), severe infections (26\%), and asphyxia (23\%). Low birth weight is an important indirect cause of death. Maternal complications in labour carry a high risk of neonatal death[1].

The shared relationship between mothers and their newborn leads to common risk factor \&etiologies of infectious disease. Newborn may acquire early onset neonatal sepsis infection vertically from endogenous bacteria in the mother's reproductive tract which may or may not cause disease in mother but can cause disease in new born.

Although studies in India show a predominance of gram negative bacterial sepsis among infants, contributing to infant mortality, a low incidence of GBS infection has been reported from many Asian countries. The reasons for the low incidence in the Asian population are unclear but may be partly due to low rates of colonization or due to intrapartum antibiotic administration to the mother with risk factors[2].

It is studied and proved that the composition of the vaginal ecosystem is not static but changes over time and in response to endogenous and exogenous influences,
Variables include stage of the menstrual cycle, pregnancy, use of contraceptive agents, frequency of sexual intercourse, specific sexual partners, vaginal douching, use of panty liners or vaginal deodorants, and utilization of antibiotics or other medications with immune or endocrine activities. Exposure to an altered milieu will cause a fluctuation in the local environment and heighten or diminish the selective advantage of specific vaginal microbes[3].

Some of these factors were difficult to control in this study, However, this study carried out in this rural community the influence of various exogenous factors appears to suggest that they have minimal effects in determining the microflora of female lower genital tract. But the effect of ethnic and genetic composition of our women require further independently verification in this community as suggested by other workers.

Antonio MA et al studied the microbiota of the lower female genital tract is adynamic, complex example of microbial colonization, the regulation of which is not fully understood. Much of what we know about the bacterial composition of the female genital tract is derived from qualitative, descriptive studies. Such studies are weakened by intrinsic technical limitations.

Often, even the usefulness of qualitative data is negatively affected by inappropriate or suboptimal methods of data collection, failure to use appropriate transport systems or enriched media, or a lack of stringent anaerobic techniques in the processing and culture of specimens. Isolation techniques used before the 1970s resulted in an underestimation of the importance of anaerobic bacteria as major constituents of the normal microbiota of the female genital tract [4].

When a very simple microbiota exists, as it does in young adolescents, lactobacilli are usually dominant, and when only a single isolate is recovered, it is usually a Lactobacillus species. Sexual activity, tampon use, childbirth, and various other occurrences in the reproductive life of women are associated with an 
Original Research Article

increasing complexity of the microbiota. Within colonized tissues, what constitutes a pathogen is dependent not only on the type of "offending" microorganism and its intrinsic virulence but also on the species complexity of the microbiota- that is, the relative dominance, in numbers, in individual a symptomatic patients. The mere presence of a potentially pathogenic species does not necessarily cause disease as defined in terms of symptoms. However, women who are intensively colonised with a high bacterial load, are more likely to still be colonised at delivery and to transmit infection to the baby.

Vaginal microbiome studies provide information that may change the way we define vaginal flora. Normal flora appears dominated by one or two species of Lactobacillus. Significant numbers of healthy women lack appreciable numbers of vaginal lactobacilli. Bacterial vaginosis (BV) is not a single entity, but instead consists of different bacterial communities or profiles of greater microbial diversity than is evident from cultivation-dependent studies. BV should be considered a syndrome of variable composition that results in different symptoms, phenotypical outcomes, and responses to different antibiotic regimens. This information may help to elucidate the link between $\mathrm{BV}$ and infection-related adverse outcomes of pregnancy[5].

Hansen SM et al studied the population dynamics of Streptococcus agalactiae (group B streptococci [GBS]) colonization of the vagina and anorectal area was investigated in a cohort of 77 Danish women during and after their pregnancy by a new sensitive method. Newborns and young infants usually carried the same GBS clone as their mothers. However, only twice were identical clones of GBS detected in different women in contrast to the observed clonal relationships of clinical isolates. These observations strongly suggest differences in the properties and epidemiology of virulent GBS clones compared to clones commonly carried by healthy individuals[6].

Stoll BJ, Schuchat A. et al also did a similar study like us regarding maternal carriage of group $\mathrm{B}$ streptococci in developing countries Group B streptococcus (GBS) is a leading cause of neonatal sepsis in many industrialized countries, but reports from the developing world infrequently identify this pathogen among newborns with sepsis. Studies of GBS colonization among women living in developing countries were reviewed to determine whether lower colonization rates might account for these findings. They concluded that although there is significant geographic variation in the proportion of women colonized with GBS, the range of colonization reported from developing countries is similar to that identified in populations studied in the United States. Specimen collection and microbiologic methods are important factors in identification of women colonized with GBS[7].

Mändar $\mathrm{R}$ et al aim was to study the initial microbial colonization of the newborns by comparing it with their mothers' vaginal microflora. Nineteen mother-newborn pairs were examined at delivery. They found a close association, both qualitative and quantitative, between the individually different microflora of a mother's vagina and that of her newborn.

The degree of contamination of the newborn significantly correlated with the counts of microorganisms found in the vagina of mothers. In $85 \%$ of investigated individual mother-newborn pairs we revealed similar predominant microorganisms. There were no cases of the mothers and their newborns harbouring similar potentially pathogenic prevailing microorganisms[8].

Spontaneous early preterm labour associated with abnormal genital bacterial colonization was studied by Lamont RF et al. The association between infection and preterm labour was studied in 72 women in spontaneous preterm labour between 26 and 34 weeks gestation and in 26 control subjects having an elective caesarean section at the same gestational age. The genital microbial flora of each group was studied comprehensively and included mycoplasmas, chlamydiae, ureaplasmas and anaerobes. Subsequent neonatal infection and chorioamnionitis was also studied.

Abnormal bacterial colonization, the presence of ureaplasmas, heavy growth of mycoplasmas and chorioamnionitis were all found significantly more often in the study group. This supports the premise that a significant proportion of idiopathic preterm labour is associated with infection and this may permit better prediction and prevention of preterm birth. The continued use of tocolytics should depend upon the identification of the presence or absence of infection. Infection appeared to be the result rather than the cause of ruptured membranes. A recommendation with respect to the classification of abnormal or normal bacterial colonization between 26 and 34 weeks is suggested on the basis of strict criteria[9].

The prevalence of maternal colonisation also varies between communities according to socioeconomic and ethnic group. E.Coliin vagina act as a reservoir for transmission of infection in the neonate. In the present study E.Coli isolated from high vaginal cultures is $23.4 \%$ and from perianal culture is $55.4 \%$ and total predominant gram negative isolates is $76.4 \%$.) Reported 
Predominant organism isolated gram negative aerobic and anaerobic pathogens $(76.2 \%)$ which is similar to our study. who have reported higher incidence of Gram negative organism.

Tameliene et.al from Kaunas reported prevalence of E.Coli colonization was higher $19.9 \%$. They did a study to evaluate the prevalence of maternal and neonatal colonization with group B streptococcus (GBS) and Escherichia coli, and examine GBS serotypes and susceptibility to antibiotics. A prospective cross-sectional study was carried out in Lithuania.

Lower vaginal/rectal swabs were obtained from pregnant women $(n=998)$ and ear canal/throat swabs were obtained from their newborns $(n=827)$ for culture. Overall, maternal and neonatal GBS colonization rates were $15.3 \%$ and $6.4 \%$, respectively. Overall, maternal and neonatal $E$. coli colonization rates were $19.9 \%$ and $14.4 \%$, respectively. The majority of $E$. coli-colonized newborns were contaminated with maternal fecal, but not vaginal, E. coli strains. Similar results were found in our study and ourconclusions are matching with the different studies quoted above[10].

\section{Conclusion}

Predominantbacteria isolated in vagina is E.Coli and second most common is Staphylococcus aureus.Predominant bacteria isolated from perianal region is E.Coli. GBS infection is very less in this region single case of GBS $(0.6 \%)$ from vaginal culture is reported.

There is significant correlation between bacteria isolated from blood culture of babies having sepsis and bacteria isolated from their mother's vaginalregion. However, it is seen that $37.7 \%$ of babies admitted in NICU who were exposed to one or more maternal risk factors is diagnosed neonatal sepsis. Although significant association between maternal genital colonization of bacteria with maternal risk factor was not demonstrated

\section{Inference-}

Genetic association studies needed to suggest that interindividual differences in the composition of vaginal microflora and susceptibility to adverse pregnancy outcomes appear to be a result, at least in part, of polymorphisms in genes encoding modulators of innate mucosal immunity. The available data do not allow us to conclude any result.No single factor is responsible for maternal and neonatal morbidity, the bacteria which is nonpathogenic in mother may become pathogenic attributed with other factors

\section{Funding: Nil, Conflict of interest: Nil Permission from IRB: Yes}

\section{References}

1. Taha TE, Biggar RJ, Broadhead RL, Mtimavalye LA, Miotti PG, Justesen AB, Liomba GN, Chiphangwi JD. Effect of cleansing the birth canal with antiseptic solution on maternal and newborn morbidity and mortality in Malawi: clinical trial. Bmj. 1997 Jul 26;315(7102):21620.

2. Bang AT, Bang RA, Baitule S, Deshmukh M, Reddy $\mathrm{MH}$. Burden of morbidities and the unmet need for health care in rural neonates-a prospective observational study in Gadchiroli, India. Indian pediatrics. 2001 Sep 1;38(9):952-66.

3. Cutland CL, Madhi SA, Zell ER, Kuwanda L, Laque M, Groome M, Gorwitz R, Thigpen MC, Patel R, Velaphi $\mathrm{SC}$, Adrian P. Chlorhexidine maternal-vaginal and neonate body wipes in sepsis and vertical transmission of pathogenic bacteria in South Africa: a randomised, controlled trial. The Lancet. 2009 Dec 11;374(9705):1909-16.

4. Antonio MA, Rabe LK, Hillier SL. Colonization of the rectum by Lactobacillus species and decreased risk of bacterial vaginosis. The Journal of infectious diseases. 2005 Aug 1;192(3):394-8.

5. Lamont RF, Sobel JD, Akins RA, Hassan SS, Chaiworapongsa T, Kusanovic JP, Romero R. The vaginal microbiome: new information about genital tract flora using molecular based techniques. BJOG: An International Journal of Obstetrics \& Gynaecology. 2011 Apr 1;118(5):533-49.

6. Hansen SM, Uldbjerg N, Kilian M, Sørensen UB. Dynamics of Streptococcus agalactiae colonization in women during and after pregnancy and in their infants. Journal of clinical microbiology. 2004 Jan 1;42(1):83-9.

7.Stoll BJ, Schuchat A. Maternal carriage of group B streptococci in developing countries. The Pediatric infectious disease journal. 1998 Jun 1;17(6):499-503

8. Mändar R, Mikelsaar M. Transmission of mother's microflora to the newborn at birth. Neonatology. 1996; 69(1):30-5.

9. Lamont RF, Taylor-Robinson D, Newman M, Wigglesworth J, Elder MG. Spontaneous early preterm labour associated with abnormal genital bacterial 
colonization. BJOG: An International Journal of Obstetrics \& Gynaecology. 1986 Aug 1;93(8):804-10.

10. Tamelienė R, Barčaitė E, Stonienė D, Buinauskienė J, Markūnienè E, Kudrevičienè A, Vitkauskienė A,
Jomantienè D, Nadišauskiené RJ. Escherichia coli colonization in neonates: prevalence, perinatal transmission, antimicrobial susceptibility, and risk factors. Medicina. 2012;48(2):71-6.

\section{How to cite this article?}

Sultan R, Harit J, Roy PK. Study of bacterial flora in perianal region and vagina and relation to neonatal outcome. Obs Rev:J obstet Gynecol 2017;3(4):56-62.doi:10.17511/joog.2017.i04.05. 